\title{
UPRAVLJANJE TEKUĆIM SREDSTVIMA I OBRTNIM KAPITALOM
}

\section{CURRENT ASSET MANAGEMENT AND CURRENCY CAPITAL}

\section{Slobodan Nićin}

Evropski univerzitet Brčko distrikt, Brčko, Bosna i Hercegovina

\section{Vojislava Grbić}

Visoka škola strukovnih studija za menadžment i poslovne komunikacije, Sremski Karlovci, Srbija

\section{Zlatan Lukić}

Univerzitet u Sarajevu, Fakultet političkih nauka, Sarajevo, Bosna i

Hercegovina

\section{CMESTE}

JEL Category: D24, E22, G32

\begin{abstract}
Apstrakt
Funkcionisanje preduzeća kao sistema započinje pribavljanjem njegovih elemenata: radne snage, sredstava za rad i predmeta rada (materijala) u cilju izvršavanja određenog zadatka. Ova sredstva su neophodna za obavljanje delatnosti u preduzeću i bez njih se ne može obavljati proces reprodukcije. Može se reći da su sredstva određeni ekonomski resursi koje kontroliše pravno lice, i rezultat su nekih prošlih događaja čijom upotrebom u budućnosti se očekuje priliv budućih ekonomskih koristi, tj. prihoda. Da bi preduzeće izvršilo svoj osnovni cilj i zadatak, i postiglo što veći profit za sebe $i$ društvo u celini, angažuje pored radne snage i određena sredstva. Sredstva koja preduzeće dobija od drugih i sredstva koja stiče tokom poslovanja čine imovinu preduzeća. Imovina pretpostavlja ukupnu vrednost svih sredstava s kojima preduzeće raspolaže, ali kako deo sredstava mora vratiti ulagaču, onda se samo onaj deo koji ostaje u trajnom vlasništvu preduzeća naziva ,čistom imovinom“. Tokom procesa rada sredstva se troše $i$ osnovni zadatak preduzeća je da sredstva obnavlja, a po mogućnosti i stalno povećava, jer je to uslov povećanja obima poslovanja i kontinuiteta preduzeća. Izražavanje, merenje, kontrola i usmeravanje finansijskog uspeha korporacije je ključna upravljačka aktivnosti u pravcu kontinuiranog poboljšanja njenog finansijskog položaja. Od toga kako menadžment shvata važnost ove kontrolno - upravljačke aktivnosti, kao i od organizacione strukture konkretnog poslovnog sistema, zavisi primenjeni sistem iskazivanja finansijskog uspeha korporacije.
\end{abstract}

Adresa autora zaduženog za korespodenciju:

Slobodan Nićin

莑=bobanicin@yahoo.com
Ključne reči: sredstva, neto obrtni fond, obračunski period, kontinuitet, bilans stanja 


\section{Abstract}

Functioning of a company as a system begins with the acquisition of its elements: labor, resources and work items (materials) in order to perform a certain task. These funds are necessary for doing business in the company and without them the reproduction process cannot be performed. It can be said that the funds are certain economic resources controlled by a legal entity and are the result of some past events whose use in the future is expected to inflow of future economic benefits, that is, the primacy. In order for an enterprise to fulfill its primary goal and task, and to achieve as much profits for itself and society as a whole, it engages the workforce and certain resources. Assets that the company receives from others and assets acquired during the course of business constitute the assets of the company. Assets presuppose the total value of all assets with which the enterprise holds, but as part of the assets must return it to the investor, then only the part that remains in the permanent ownership of the enterprise is called "net assets". During the process of working the funds are spent and the basic task of the company is to renew the funds, and if possible, it constantly increases, as this is a condition for increasing the volume of business and continuity of the company. Expressing, measuring, controlling and directing the financial success of a corporation is a key management activity in the direction of continuous improvement of its financial position. From the way the management understands the importance of this control-management activity, as well as the organizational structure of a particular business system, the applied system of expressing the financial success of the corporation depends.

Keywords: Assets, Net Working Capital, Accounting Period, Continuity, Balance Sheet

\section{TEKUĆA SREDSTVA}

Prema pojavnim oblicima sredstva preduzeća mogu biti: sredstva u obliku novca (odnosno vrednosnih papira), sredstva u obliku stvari, i sredstva u obliku prava. Prema trajanju korišćenja sredstava, imovina preduzeća razvrstava se na: dugotrajnu imovinu i kratkotrajnu imovinu. Dugotrajnu imovinu čine osnovna sredstva, a kratkotrajnu imovinu čine obrtna sredstva.

Drugu značajnu grupu sredstava u aktivi čine tekuća sredstva, koja uz stalna sredstva predstavljaju najvažniji faktor za uspešno obavljanje proizvodnih ciklusa. Premda su u industrijskim preduzećima stalna sredstva najvažnija po veličini po svom udelu i značaju za odvijanje tehnološkog procesa, nemoguće je zamisliti uredno funkcionisanje proizvodnje bez određene veličine tekućih sredstava. Svaki uloženi evro stalnih sredstava zahteva i angažovanje određene količine tekućih sredstava, pa će zbog toga biti potrebno analiziranje uloge ove grupe aktivnih pozicija svakog bilansa.

Tekuća sredstva tretiraju se kao kratkoročna imovina u preduzeću. Prema tome, tekuću ili kratkoročnu imovinu čine ona sredstva za koja se očekuje da će se pretvoriti u novčani oblik u razdoblju kraćem od jedne godine. Međutim, pri definisanju tekuće kratkoročne imovine treba uklučiti kriterijume normalnog trajanja proizvodnog procesa. U nekim svojim elementima biće potrebna i svestranija i dublja analiza, jer se brzim obrtanjem ukupnih tekućih sredstava ulažu često puta velika novčana sredstva u proizvodne procese, pa je zbog toga itekako važan efekat koji ostvarujemo takvim ulaganjem.(Dervišević, 2008)

Tekuća (obrtna) sredstva čine novac potreban za tekuća planiranja, materijal i sirovine radi ulaganja u proizvodnju, vrednosti utrošene u proizvodnju i proizvodi koji čekaju prodaju.

Obrtna sredstva čini i novac dat dobavljačima pre isporuke robe, kao i potraživanja od kupaca od momenta isporuke proizvoda, odnosno pružanje usluge do momenta naplate. Ta sredstva se neprestano obrću (cirkulišu) u poslovnom procesu. Međutim, potrebno je uvek raspolagati jednim njihovim delom kako bi se nesmetano odvijao poslovni proces. Upravo za taj deo treba osigurati novac već prilikom poslovnih ulaganja, i to tako da taj iznos novca bude na raspolaganju duži vremenski period.

Treba imati u vidu činjenicu da ni jedna od navedenih definicija obrtnih sredstava nije sveobuhvatna. Najbliži pojam je tekuća aktiva. Osim toga, često se pojam obrtna sredstva poistovećuje terminima radnog kapitala, pri čemu se uvode i dva nova pojma i to:

- bruto radni kapital

- neto radni kapital.

Prema pojavnim oblicima tekuća sredstva bi se mogla svrstati u tri osnovne grupe i to: 
a) tekuća sredstva u novčanom obliku (gotovina u kasi i na žiro računu te ekvivalenti gotovine). Novčani oblik predstavlja početni i završni oblik obrtnih sredstava, koji može biti u blagajni ili na depozitnim računima.

b) tekuća sredstva u naturalnom obliku (zalihe materijala, nedovršene proizvodnje, gotovih proizvoda, robe). Naturalni oblik zavisno od mesta u reprodukcionom ciklusu preduzeća može da bude u različitim vidovima, to su :

- sirovine i materijal

- nedovršena proizvodnja i

- gotovi proizvodi

c) tekuća sredstva u prelaznom oblikupredstavlja vrednost pretraživanja koja mogu da nastanu po nekoliko osnova i to:

- prodaja gotovih proizvoda kupcima, i

- davanje avansa dobavljačima ili davanje kredita.

\section{ANALITIČKI ASPEKTI OBRTNIH SREDSTAVA}

$\mathrm{Za}$ potrebe finansijske analize i finansijskog upravljanja u preduzeću, obrtna sredstva se dele na ukupna i neto obrtna sredstva. Pod ukupnim sredstvima podrazumevaju se sva ulaganja koja preduzeća vrše u pojedine, konkretne oblike obrtnih sredstava. Neto obrtna sredstva se definišu kao razlika između tekuće aktive i tekuće pasive, odnosno kao razlika između ukupnih obrtnih sredstava i ukupnih kratkoročnih obaveza preduzeća (Nićin i Nićin, 2017).

Kao najvažniji izvori koji dovode do priliva neto obrtnih sredstava navodi se sledeće: redovno poslovanje u slučaju kada su ukupni prihodi veći od rashoda koji su nastali kao posledica trošenja obrtnih sredstava, prodaja osnovnih sredstava i dugoročnih ulaganja za gotovinu i preuzimanje dodatnih dugoročnih zajmova.

Do smanjenja, odnosno odliva neto obrtnih sredstava najčešće dolazi po osnovu sledećih ključnih razloga: kada su prihodi od redovnog poslovanja manji od rashoda koji su nastali kao posledica trošenja obrtnih sredstava; zbog kupovine osnovnih sredstava; zbog otplate zajmova.

Ukupna obrtna sredstva najbolje reprezentuju sume tekuće aktive u bilansu stanja preduzeća. Ona se sastoje iz pojedinih konkretnih oblika sredstava, odnosno pozicije aktive kao što su: novčana sredstva u blagajni i na računima, potraživanje od kupaca, tržišne hartije od vrednosti, menice i akcepti primljeni od kupaca, dati avans dobavljačima, zalihe i unapred plaćeni rashodi i obračunati, a nenaplaćeni prihodi (aktivna vremenska razgraničenja).

\section{STUKTURA AKTIVE I PASIVE OBRTNIH SREDSTAVA}

Za ocenu za finansijske strukture preduzeća koriste se informacije iz bilansa stanja. Aktiva bilansa stanja mora biti tako struktuisana da omogući kontinuitet finansiranja poslovne aktivnosti. Shodno tome, menadžment je više zainteresovan za strukturu obrtnih sredstava nego za strukturu poslovnih sredstava.

U strukturi obrtnih sredstava najzastupljenije su zalihe materijala, nedovršene proizvodnje i gotovih proizvoda. Zalihe su namenjene za održavanje poslovnog ciklusa. One se pretvaraju u novac u okviru jednog poslovnog ciklusa koji traje najduže do jedne godine, tako da imaju tretman tekuće imovine. Prodajom gotovih proizvoda sa zaliha, troškovi njihove nabavke se prenose na troškove prodate robe $\mathrm{i}$ tako suočavaju sa prihodima od prodaje. Zalihe i potraživanja od kupca se klasifikuju kao tekuća imovina, čak iako se pretvaranje te imovine u novac neće dogoditi u periodu do jedne godine.

$\mathrm{U}$ bilansu se tekuća imovina klasifikuje prema stepenu likvidnosti na: novac, hartije od vrednosti, potrživanja, zalihe i unapred plaćene rashode. Klasifikacija izvora finansiranja obrtnih sredstava vrši se sa aspekta ročnosti i porekla.

Prema ročnosti, izvore finansiranja obrtnih sredstava delimo na:

- kratkoročne (do jedne godine: vrednosni papiri do jedne godine, obaveze prema dobavljačima, unapred naplaćeni prihodi, naplaćeni rashodi i sl.)

- dugoročne izvore finansiranja (preko jedne godine)

- ročni (dugoročni krediti, emisija obveznica)

- neročni (trajno su raspoloživi - akcijski kapital i zadržana dobit).

Troškovi finansiranja rastu s vremenom korišćenja izvora finansiranja. Što je rok otplate kredita duži, troškovi finansiranja su veći, i obrnuto. 
Prema poreklu, izvori obrtnih sredstava mogu biti vlastiti (neročni) izvori i tuđi (ročni) izvori. Vlastiti izvori finansiranja su trajnog karaktera, za razliku od tuđih, čiji rokovi se utvrđuju ugovorom.

\section{UPRAVLJANJE SREDSTVIMA}

TEKUĆIM

Treba imati u vidu da je upravljanje obrtnim sredstvima posebno važno za mala preduzeća. Potrebi posebnog izračunavanja osnovnih principa upravljanja obrtnim sredstvima najviše doprinosi činjenica da ulaganja u obrtna sredstva predstavljaju pretežan deo ukupnih ulaganja koje vrši preduzeće, kao i to da odluke o tim ulaganjima moraju da se donose skoro svakodnevno, što nije slučaj sa odlukama o ulaganju u osnovna sredstva (Ratković- Abramović, 2011).

Upravljanje obrtnim sredstvima je važno iz nekoliko razloga. Među najbitnijim je sigurno taj što obrtna sredstva preduzeća skoro uvek čine više od polovine njenih ukupnih sredstava. Čak i one firme koje se bave uslužnim delatnostima, pa zbog toga nemaju velikih sredstava u zalihama, imaju zato najčešće značajna sredstva u potraživanjima. Ako preduzeće želi napredovati i rasti ono mora stalno kontrolisati svoje zalihe i potraživanja. Prevelika obrtna sredstva mogu dovesti do ishoda prosečnih prinosa na ulaganja, ali $s$ druge strane preduzeća sa malim obrtnim sredstvima će imati veći rizik u održavanju kontinuiteta poslovanja $\mathrm{i}$ teže je manipulisati radom takvog preduzeća.

Drugi bitan aspekt upravljanja obrtnim sredstvima jeste uticaj koji odluke o obrtnim sredstvima imaju na rizik, prihode i profitabilnost kompanije. Direktna odgovornost finansijskog menažera jeste upravljnje novcem, potraživanjima od kupaca i po osnovu vrednosnih papira, ali on isto tako ima ulogu i u upravljanju zalihama. Ove upravljačke aktivnosti zahtevaju stalan, svakodnevni angažman finansijskog menadžera. Upravljanje obrtnim sredstvima je važan segment finansijskog poslovanja, stoga je neophodno razmotriti optimalnu količinu svakog pojedinog segmenta. Zadatak upravljanja obrtnom imovinom je da omogući preduzeću da utvrdi optimalan volumen obrtnih sredstava.

Suština upravljanja zalihama je da se zalihe nabavljaju i angažuju onda kada su potrebne, u optimalnim količinama i uz minimalne troškove.
Zalihe omogućavaju fleksibilnost postavljanja preduzeća i treba in povećati dok su uštede po osnovu držanja zaliha veće od troškova njihovog držanja.

Potraživanja od kupaca nužno je svesti na što manji iznos, $s$ jedne, i što kraći rok njihovog plaćanja $s$ druge strane, te raznim merama smanjiti rizik naplate, jer to povlači sniženje troškova finansiranja i povećanja bruto dobitka. Osnov za uspešno upravljanje gotovinom čini projekcija novčanih primanja i izdataka novca, odnosno planiranje priliva i odliva novca, praćenje izveštaja i to kvartalnih, mesečnih, desetodnevnih.

Obrtna sredstva su deo obrtnih sredstava ili imovine preduzeća. Racionalno upravljanje i dobro gazdovanje ukupnim obrtnim sredstvima $i$ njihovim pojedinačnim oblicima svakako predstavlja najznačajniju preokupaciju finansijskog upravljanja preduzećem. To upravljanje pretpostavlja da se sa što manjim ulaganjima u ukupna obrtna sredstva, kao i njihove pojedinačne kategorije, ostvari što veći obim poslovne aktivnosti sa ciljem maksimiziranja profitabilnosti preduzeća kao celine, uz istovremeno održavanje potrebnog stepena njegove tekuće likvidnosti.

Finansijsko upravljanje obrtnim sredstvima ima osnovni cilj da održi povoljnu finansijsku strukturu preduzeća i zadovoljavajući stepen njegove likvidnosti. Razlike koje postoje između obrtnih i osnovnih sredstava na zasnivaju se samo na njihovim fizičkim svojstvima, već pre svega, na njihovim različitim funkcijama koje imaju u preduzeću, kao i njihovog finansiranja. Zbog toga, u cilju uspešnog realizovanja vrednosti $i$ jednih $i$ drugih sredstava, neophodno je da in finansijski menadžment preduzeća različito tretira, što podrazumeva da se vodi računa o nekoliko značajnih momenata:

1. Ulaganja $u$ obrtna sredstva $u$ potpunosti se naknađuju kroz prodajne cene proizvoda ili usluga u periodima kraćim od jedne godine, odnosno u toku jednog poslovnog ciklusa preduzeća, dok je za naknadu ulaganja u osnovna sredstva potreban znatno duži vremenski period.

2. Obrtna i osnovna sredstva imaju različite stepene fleksibilnosti.

3. Finansijski principi koji se primenjuju pri upravljanju obrtnim sredstvima razlikuju se od 
onih koji su relevantni za finansijsko upravljane osnovnim sredstvima.

4. Povećanje obrtnih sredstava se najvećim delom finansira iz kratkoročnih finansijskih izvora.

Pored navedenih elemenata postoje i mnogi drugi razlozi koji neposredno ili posebno indiciraju potrebu da se problematika finansijskog upravljanja obrtnim sredstvima ipak posebno izuči i prikaže u okviru celokupne problematike finansijskog upravljanja preduzeća.

Kao najvažniji argumenti koji idu u prilog ovakvoj tvrdnji, moglo bi se navesti: značajno vreme koje se posvećuje upravljanju obrtnim sredstvima od strane menadžmenta preduzeća, obim ulaganja u obrtna sredstva preduzeća, odnos između povećanja obima prodaje (realizacije) i obrtnih sredstava, kao i značaj obrtnih sredstava za mala preduzeća.

Kao prikladan instrument upravljanja finansijama korporacije može da posluži, u skladu sa idividualnim prilikama korporacije, odmerena marža sigurnosti koja se naziva neto obrtni fond ili neto obrtna sredstva.

Pomenuti nazivi, od kojih je prvi evropskog, a drugi anglo-saksonskog porekla, izražavaju računsku veličinu, izvedenu iz bilansa stanja, koja je posmatrana iz perspektive aktive - neto obrtna sredstva, a iz perspektive pasive - neto obrtni fond.

Dakle, reč je o istoj računskoj veličini, koja predstavlja višak duguročnog kapitala preko neto imobilizacija (neto obrtni fond), odnosno višak obrtnih sredstava preko kretkoročnih obaveza (neto obrtna sredstva). U oba slučaja radi se o delu obrtnih sredstava koja su finansirana dugoročnim kapitalom - sopstvenim i pozajmljenim.

Po svojoj iskaznoj moći, neto obrtni fond predstavlja sigurnosnu mrežu, koja se u praksi analize finansijskog položaja koristi kao kriterijum za utvrđivanje i ocenu finansijskog ekvilibrijuma, kao pretpostavke održavanja likvidnosti. Karakter sigurnosne mreže proizilazi iz dugoročnosti njegovog dospeća, koja olakšava usaglašavanje brzine priliva gotovine po osnovu naplate potraživanja sa brzinom dospevanja obaveze za izmirivanje.
Potreba za neto obrtnim fondom uslovljena je okolnošću da je deo obrtnih sredstva dugoročno vezan (zalihe), ali, ne retko, iz zahteva kreditiranja liferanata kroz avanse ili kupca kroz prodaju na odloženo plaćanje. Pošto su visina zaliha, uslovi njene nabavke i brzina obrtanja potraživanja individualno uslovljeni, što znači da zavise od vrste i veličine korporacije, stope rentabilnosti, politike nabavke i prodaje, odnosa sopstvenog $\mathrm{i}$ pozajmljenog kapitala, uslova korišćenja dugoročnih zajmova, političke ekspanzije, pa i ljudskog faktora, dobro upravljanje finansijama korporacije pretpostavlja poznavanje potrebnog neto obrtnog fonda.

Potrebni neto obrtni fond za pojedinačne korporacije predstavlja ,normalu“, koja je ishodište za komparaciju sa stanjem na određeni dan, iz koje proizilaze razlike koje se uzimaju kao kriterijum za ocenu kvaliteta finansijske strukture i mogućnosti održavanja likvidnosti i garantovanja optimalne rentabilnosti. Ako normala nije fiksirana unapred ili je analitičar ne poznaje, što je slučaj sa eksternim analitičarem, ona (normala) se fingira u visini zaliha ili u visini polovine ukupnih obrtnih sredstava, pod uslovom da su obrtna sredstva dvostruko veća $(200 \%)$ od kratkoročnih obaveza, a što naročito koriste kreditori (bankari).

U slučaju fingiranja normale na pomenuti način, ocena finansijskog položaja pretpostavlja uzimanje u obzir varijacija neto obrtnog fonda $u$ nizu sukcesivnih obračunskih perioda.

Pridavanje značaja varijacijama neto obrtnog fonda u nizu sukcesivnih obračunskih perioda rezultira iz uverenja da one:

- otkrivaju brzo i lako tendencije u razvoju finansijske srukture korporacije,

- obezbeđuju rekonstrukciju istorije finansiranja u prošlosti, koja pokazuje koji su izvori finansiranja bili predominantni, kakva je bila veličina i učestalost trošenja, koliko je bilo eksternog finansiranja $u$ odnosu na samofinansiranje, i

- snabdevaju rukovodstvo korporacije indikacijama solventnosti na dugi rok.

Inače, promene neto obrtnog fonda u sukcesivnim obračunskim periodima, koje se ipoljavaju kao popravljanje ili pogoršanje finansijske strukture, uvek su rezultanta povećanja ili smanjenja bilansnih veličina iza kojih se neto obrtni fond 
izvodi. Odnosna povećanja ili smanjenja su uslovljena, i to:

- prihodima većim od ukupnih rashoda bez amortizacije,tj. ako je protok novca pozitivan,

- prodajom osnovnih sredstava (dezinvestiranje),

- povećanjem dugorošnih zajmova (eksterno finansiranje),

- konverzijom kratkoročnih u dugoročne zajmove, i

- dekapitalizacijom kroz povećanje osnovnog kapitala (interno finansiranje).

U svim pomenutim slučajevima smanjuje se visina imobilizacije kao odbitne pozicije od dugoročnog kapitala ili se povećava visina dugoročnog kapitala, što ima za posledicu porast neto obrtnog fonda.

Obrnuto, nabavka osnovnih sredstava (investiranje), isplata sopstvenog kapitala i dugoročnih zajmova (definisanje) i poslovanje sa gubitkom ima za posledicu povećanje vrednosti imobilizacija i smanjenje dugoročnih kapitala, iz čega rezultira smanjenje raspona između dugoročnog kapitala i imobilizcije, a time i smanjenje neto obrtnog fonda. Odnosne promene u suprotnim smerovima, povećanje imobolizacija i smanjenje dugoročnog kapitala - mogu da prouzrokuju pojavu negativnog neto obrtnog fonda, u tom slučaju je neto obrtni fond pokazatelj finansiranja dela imobilizacija kratkoročnim obavezama što je, po pravilu, praćeno pojavom opasne nelikvidnosti, koja zvoni na uzbunu i nagoveštava predstečajnu situaciju.

Izvlačenje zaključaka o finansijskom položaju zasniva se na tabeli, koja se sastavlja na osnovu elemenata bilansa stanja.

\section{OBRTNI KAPITAL I UPRAVLJANJE NETO OBRTNIM SREDSTVIMA}

U najužem smislu obrtni kapital predstavlja razliku između kratkotrajne imovine i kratkoročnih obaveza kompanije. U praksi se još naziva i neto radni kapital. Obrtni kapital uslov je likvidnosti i finansijske stabilnosti kompanije, te u suštini daje odgovor o tome koliko je likvidne imovine kompanije na raspolaganju na održavanje i širenje poslovanja. Vrednost obrtnog kapitala može biti pozitivna ili negativna, a zavisi od strukture imovine i dugova kompanije.
Obrtni kapital $=$ kratkotrajna imovina - kratkoročne obaveze

U pravilu se smatra da će kompanije koje imaju višu razinu obrtnog kapitala dugoročno bolje poslovati budući da su u svakom trenutku sposobne proširiti, unaprediti ili izmeniti operativno poslovanje. Što je viši nivo obrtnog kapitala, kompanija je pod manjim pritiskom tržišta i sposobnija je samostalno finansirati rast poslovanja. Upravo zbog toga mnogo finansijskih stručnjaka pri proceni vrednosti kompanije prvo uzme bilans stanja i proveri nivo obrtnog kapitala. To im omogućuje da u trenutku donesu načelnu procenu o budućnosti kompanije i potencijalne probleme/mogućnosti.

Posebnu pažnju obrtnom kapitalu valja posvetiti kada pokrećemo poslovanje, bez obzira bio to mali preduzetnički poduhvat ili velika kompanija. Znamo da mnoge kompanije i preduzetnici najčešće propadaju i posustaju u prvih nekoliko godina od početka poslovanja. Jedan od bitnih faktora za takve događaje upravo je neadekvatno osiguranje obrtnog kapitala. Obrtni kapital su sredstva potrebna da bi kompanija premostila vreme od trenutka kada odluči da proizvede neki proizvod ili uslugu do trenutka kada primi prvu uplatu kupaca za proizvod ili izvršenu uslugu. Pojednostavljeno, to je iznos koji preostane od uplaćenog kapitala nakon što smo kupili svu potrebnu imovinu za početak poslovanja.

Menadžment obrtnog kapitala obuhvata aktivnosti koje su povezane sa kratkoročnim sredstvima $i$ kratkoročnim dugovima iz poslovanja. Radi se o odlučivanju o obimu obrtnih sredstava i obaveza do dobavljača koji utiče na zaduženost kompanije odnosno utiče na donošenje odluka o obimu potrebnih novčanih sredstava koja su potrebna za osiguranje platne sposobnosti kompanije.

Smanjivanjem obima sredstava koja su „vezana“ u poslovnom procesu, smanjujemo potrebe po izvorima finansiranja, što snižava troškove poslovanja. Prilikom razvijanja rasprave o bruto kapitalu, njegovom značenju i menadžmentu, oslonac tražimo u računovodstvenom poimanju i podeli sredstava na stalna i obrtna sredstva (Rodić i Filipović, 2010).

Za kontinuitet poslovnog procesa neophodno je obezbediti optimalna finansijska sredstva. Nedostatak obrtnih sredstava izaziva poremećaje 
u likvidnosti, a kasnije i u solvetnosti. Problem likvidnih sredstava se odnosi na kratkoročno finansiranje, odnosno upravljanje obrtnim sredstvima. Uparavljanje obrtnim sredstvima obuhvata novac, novčane ekvivalente, potrživanja, zalihe i kratkoročne obaveze. Ono je najčešće usmereno na optimizaciju novca, hartija od vrednosti, potraživanja i zaliha, a pri tom izostaje optimizacija drugih likvidnih sredstava. Optimizacija se odnosi na uravnoteženje odnosa u ukupnoj strukturi sredstava. Efikasno upravljanje obrtnim sredstvima zahteva prethodnu zanalizu obrtnih sredstava sa aspekta likvidnosti.

Prema stepenu likvidnosti razlikujemo tekuću aktivu:

- I stepen likvidnosti (gotovina u blagajni, depoziti po viđenju, hartije od vrednosti koje su odmah unovčive),

- II stepena likvidnosti (hartije od vrednosti unovčive za 30 dana, potraživanja od kupaca naplativa do 30 dana) $i$

- III stepena likvidnosti (kratkoročna potraživanja naplativa preko 30 dana i zalihe gotovih proizvoda, zalihe sirovine i materijala).

Ovakvu podelu tekuće aktive treba shvatiti uslovno, iz razloga što neke stavke aktive svrstane u kategoriju manje likvidne aktive mogu biti brže unovčive od stavki koje su svrstane u brzo likvidnu aktivu. Unovčivost zavisi od intenziteta tržišta (pada li ili raste), ponude i potražnje finansijskih instrumenata, količine novca u opticaju, visine kamatne stope inflacije, i sl.

Uzroke nelikvidnosti treba tražiti u nedostatku trajnih obrtnih sredstsva, lošem upravljanju zaliha, nenamenskom povlačenju gotovine iz opticaja (najčešće od strane vlasnika), te u ulaganju likvidnih sredstava u osnovna sredstva.

Ipak, najčešći uzrok nelikvidnosti je u slabom planiranju i kontroli priliva i odliva gotovog novca. Menadžment se uglavnom rukovodi podacima o stanju novca na žiro račun, trenutnom dugovanju i obavezama, bez planiranja novčanih tokova. Ukoliko se u nekom periodu pojavi suficit novca na žiro račun, a nema prispelih obaveza, menadžment donosi odluku o ulaganju u fiksnu aktivu ili neproduktivne namene (renoviranje, kupovinu službenog auta i sl.). Sigurno je da će takvo preduzeće morati u skorije vreme nestašicu novca pokrivati kreditima i pozajmicama.
Planiranje priliva $\mathrm{i}$ odliva novca, te kontrola planiranog ostvarenja sve više postoje osnovni istrumenti upravljanja finansijama. Prilivi i odlivi novca se planiraju i prate kroz gotovinski tok. Veći priliv od odliva govori da je gotovinski tok pozitivan. Ukoliko je neto rezultat perioda negativan, moguće je nedostatak sredstva pokriti suficitom prethodnog perioda. Ukoliko sredstva prethodnog perioda nisu dovoljna za pokriće deficita tekućeg perioda, preduzeće je ušlo u zonu nelikvidnosti. Pored svoje značajne uloge u finansijskom upravljanju, izveštaj o gotovinskom toku je važan instrument za ocenu buduće likvidnosti od strane kreditora.

Veliki udar na likvidnost preduzeća ima porez na dodatnu vrednost. Bez obzira što preduzeće ostvaruje pravo na odbitak ulaznog poreza za nabavku zaliha i osnovnih sredstava, ono mora u startu izdvojiti novčana sredstva. To je dodatno opterećenja za pravne obveznike koji u pojedinim periodima imaju veći ulazni od izlaznog poreza na dodatnu vrednost. Više uplaćeni porez se smatra poreskim kreditom za naredni obračunski period, osim kod izvoznih poslova gde postoji mogućnost ostvarivanja prava na povrat. Pravo na povrat nemaju pravna lica koja se nisu registrovala $u$ sistem PDV-a, što ih dovodi u nepovratnu situaciju (Vujnović-Gligorić, 2008).

Kad se poslovni proces okonča, slobodan novac se ponovo vraća u svoje izvore. Okosnicu finansiranja predstavlja modeliranje odnosa između aktive i pasive obrtnih sredstava. Iznos optimalnog obrtnog (radnog) kapitala varira sa veličinom organizacije i prirodom njene poslovne aktivnosti. Analitičari, koji poznaju prirodu poslovanja, mogu utvrditi iznos obrtnog kapitala koji je potreban da bi kompanija bila na zadovoljavajućem finansijskom položaju. Ukoliko su kratkoročne imovine, preduzeće ima negativan iznos obrtnog kapitala. Negativan iznos obrtnog kapitala ne mora značiti da je kompanija insolventna. Mnoge kompanije iz oblasti telefonskih usluga pripadaju takvoj kategoriji.

Da li neko preduzeće ima kvalitetne izvore finansiranja obrtnih sredstava, najlakše možemo utvrditi iz bilansa stanja. Kvalitete finansiranja obrtnih sredstva ogleda se $u$ postojanju adekvatnih dugoročnih i trajnih izvora. Ukoliko preduzeće nema takvih izvora, znači da se celokupno poslovanje finansira iz kratkoročnih 
izvora i da postoji opasnost od nelikvidnosti. Podaci iz bilansa stanja nisu dovoljni da utvrdimo potrebu za trajnim obrtnim sredstvima. Da bi se utvrdile stvarne potrebe preduzeća za trajnim obrtnim sredstvima, potrebno je poznavati poslovanje preduzeća, računovodstvene evidencije, te politiku nabavke i prodaje.

\section{ZAKLJUČAK}

Preduzeće, kako bi izvršilo svoj osnovni cilj i zadatak, i postiglo što veći profit za sebe i društvo u celini, angažuje pored radne snage i određena sredstva. Tokom procesa rada sredstva se troše i osnovni zadatak preduzeća je da sredstva obnavlja, a po mogućnosti stalno povećava, jer je to uslov za povećanje obima poslovanja i kontinuiteta preduzeća.

Prema trajanju korišćenja sredstava imovina preduzeća razvrstava se na dugotrajnu i kratkotrajnu imovinu. Dugotrajnu imovinu čine osnovna sradstva, a kratkotrajnu imovinu čine obrtna sredstva. U najužem smislu obrtni kapital predstavlja razliku između kratkotrajne imovine i kratkoročnih obaveza kompanije.
Obrtna sredstva čini i novac dat dobavljačima pre isporuke robe, te potraživanja od kupaca od momenata isporuke proizvoda, odnosno pružanja usluga do momenta naplate. Ta sredstva se neprestalno obrću u poslovnom procesu.

Upravljanje obrtnim sredstvima je važno iz nekoliko razloga. Među najbitnijim je sigurno taj što obrtna sredstva preduzeća skoro uvek čine više od polovine njenih ukupnih sredstava. Zadatak upravljanja obrtnom imovinom je da omogući preduzeću da utvrdi optimalan volumen obrtnih sredstava.

Izražavanje, merenje, kontrola i usmeravanje finansijskog uspeha korporacije je ključna upravljačka aktivnosti u pravcu kontinuiranog poboljšanja njenog finansijskog položaja. Od toga kako menadžment shvata važnost ove kontrolno upravljačke aktivnosti, kao i od organizacione strukture konkretnog poslovnog sistema, zavisi primenjeni sistem iskazivanja finansijskog uspeha korporacije.

\section{CITIRANA DELA}

Dervišević F. (2008), Analiza poslovanja za menadžere, Bihać

Nićin N., Nićin S. (2017), Poslovne finansije, Evropski Univerzitet, Brčko

Ratković Abramović M. (2011), Korporativne finansije, Beogradska poslovna -Visoka škola strukovnih studija, Beograd

Rodić J., Filipović M. (2010), Poslovne finansije, Beogradska poslovna škola, Visoka škola strukovnih studija, Beograd

Vujnović-Gligorić B. (2008), Poslovne finansije, Panevroski univerzitet“ APEIRON“, Banja Luka

Datum prve prijave:

Datum prijema korigovanog članka:

Datum prihvatanja članka:
23.02.2018.

01.08 .2018 .

05.09.2018.

\section{Kako citirati ovaj rad? / How to cite this article?}

\section{Style - APA Sixth Edition:}

Nićin, S., Grbić, V., \& Lukić, Z. (2018, 10 15). Upravljanje tekućim sredstvima i obrtnim kapitalom. (Z. Čekerevac, Ur.) FBIM Transactions, 6(2), 98-106. doi:10.12709/fbim.06.06.02.11

\section{Style - Chicago Sixteenth Edition:}

Nićin, Slobodan, Vojislava Grbić, i Zlatan Lukić. 2018. „Upravljanje tekućim sredstvima i obrtnim kapitalom." Urednik Zoran Čekerevac. FBIM Transactions (MESTE) 6 (2): 98-106. doi:10.12709/fbim.06.06.02.11. 
Style - GOST Name Sort:

Nićin Slobodan, Grbić Vojislava i Lukić Zlatan Upravljanje tekućim sredstvima i obrtnim kapitalom [Časopis] // FBIM Transactions / ur. Čekerevac Zoran. - Beograd : MESTE, 1510 2018. - 2 : T. 6. - str. 98-106.

Style - Harvard Anglia:

Nićin, S., Grbić, V. \& Lukić, Z., 2018. Upravljanje tekućim sredstvima i obrtnim kapitalom. FBIM Transactions, 15 10, 6(2), pp. 98-106.

Style - ISO 690 Numerical Reference:

Upravljanje tekućim sredstvima i obrtnim kapitalom. Nićin, Slobodan, Grbić, Vojislava i Lukić, Zlatan. [ur.] Zoran Čekerevac. 2, Beograd : MESTE, 1510 2018, FBIM Transactions, T. 6, str. 98-106. 